Article

\title{
Investigation of Indoor and Outdoor Fine Particulate Matter Concentrations in Schools in Salt Lake City, Utah
}

\author{
Daniel L. Mendoza ${ }^{1,2,3, *(\mathbb{D})}$, Tabitha M. Benney ${ }^{4}\left(\mathbb{D}\right.$, Ryan Bares ${ }^{5}$, Benjamin Fasoli ${ }^{1}$, Corbin Anderson ${ }^{6}$, \\ Shawn A. Gonzales ${ }^{6}$, Erik T. Crosman ${ }^{7}$ (D) and Sebastian Hoch ${ }^{1}$
}

1 Department of Atmospheric Sciences, University of Utah, 135 S 1460 E, Room 819, Salt Lake City, UT 84112, USA; benfasoli@gmail.com (B.F.); sebastian.hoch@utah.edu (S.H.)

2 Division of Pulmonary Medicine, Department of Internal Medicine, School of Medicine, University of Utah, 26 N 1900 E, Salt Lake City, UT 84132, USA

3 Department of City \& Metropolitan Planning, University of Utah, 375 S 1530 E, Suite 220, Salt Lake City, UT 84112, USA

4 Department of Political Science, University of Utah, 260 S Central Campus Drive, Salt Lake City, UT 84112, USA; tabitha.benney@poli-sci.utah.edu

5 Utah Department of Environmental Quality, Division of Air Quality, 195 N 1950 W, Salt Lake City, UT 84116, USA; rbares@utah.gov

6 Salt Lake County Health Department, Air Quality Bureau, Environmental Health Division 788 East Woodoak Lane, Murray, UT 84107, USA; canderson@slco.org (C.A.); shgonzales@slco.org (S.A.G.)

7 Department of Life, Earth and Environmental Sciences, West Texas A\&M University, Natural Sciences Building 324, Canyon, TX 79016, USA; etcrosman@wtamu.edu

* Correspondence: daniel.mendoza@utah.edu

check for updates

Citation: Mendoza, D.L.; Benney,

T.M.; Bares, R.; Fasoli, B.; Anderson,

C.; Gonzales, S.A.; Crosman, E.T.;

Hoch, S. Investigation of Indoor and

Outdoor Fine Particulate Matter

Concentrations in Schools in Salt

Lake City, Utah. Pollutants 2022, 2,

82-97. https://doi.org/10.3390/

pollutants2010009

Academic Editor: Pedro Branco

Received: 12 January 2022

Accepted: 15 February 2022

Published: 4 March 2022

Publisher's Note: MDPI stays neutral with regard to jurisdictional claims in published maps and institutional affiliations.

Copyright: (c) 2022 by the authors. Licensee MDPI, Basel, Switzerland. This article is an open access article distributed under the terms and conditions of the Creative Commons Attribution (CC BY) license (https:/ / creativecommons.org/licenses/by/ $4.0 /)$.

\begin{abstract}
Although there is mounting evidence that suggests that air pollution is impactful to human health and educational outcomes, this is especially problematic in schools with higher air pollution levels. To understand whether all schools in an urban area are exposed to similar outdoor air quality and whether school infrastructure protects children equally indoors, we installed research-grade sensors to observe $\mathrm{PM}_{2.5}$ concentrations in indoor and outdoor settings to understand how unequal exposure to indoor and outdoor air pollution impacts indoor air quality among high- and low-income schools in Salt Lake City, Utah. These data and resulting analysis show that poor air quality may impact school settings and the potential implications with respect to environmental inequality. Based on this approach, we found that during atmospheric inversions and dust events, there was a lag ranging between 35 and $73 \mathrm{~min}$ for the outdoor $\mathrm{PM}_{2.5}$ concentrations to follow a similar temporal pattern as the indoor $\mathrm{PM}_{2.5}$. This lag has policy and health implications and may help to explain rising concerns regarding reduced educational outcomes related to air pollution in urban areas.
\end{abstract}

Keywords: air quality; fine particulate matter; high schools; building ventilation; environmental inequality; research-grade sensors; indoor air quality; atmospheric inversions; dust events; urban

\section{Introduction}

Every day, around 93\% of children under the age of 15 (1.8 billion children) breathe outdoor air that is so polluted it puts their health and development at serious risk [1]. In the US, this problem is compounded by uneven monitoring of air quality, which can vary dramatically from state to state or even within different areas of a single metropolitan area. In many cases, higher pollutant concentrations noted near industrial and near-road locales result in economically disadvantaged and minority populations facing a disproportionate exposure to air pollutants. In fact, exposure rates in the US are more likely determined by economic structures (e.g., socioeconomic status) [2] and race [3,4] than any other factor. There is also mounting evidence that suggests that air pollution can be impactful to educational outcomes [5-7] and human health [8], but research has not completely demonstrated the mechanisms that produce these outcomes, and less is understood about these effects 
in school settings. This uneven exposure to environmental risks and hazards is known as environmental inequality, which is created by social, economic, and political processes that intensify or worsen economic and social inequality. This form of inequality exposes already-disadvantaged populations to the increased harms of air pollution.

When considering environmental inequality in urban areas, schools are an important setting. Children are especially vulnerable to the health and developmental impacts of pollution exposure due to their unique biological vulnerabilities, age-related patterns of exposure, and lack of control over their own environmental circumstances [9]. In addition, air pollution aggravates inequality through its connection with a variety of educational and economic outcomes. Currie [10] and others demonstrated links between poor health at birth, lower educational attainment [11], and below-average adult outcomes [12]. Economic research in this area has also illustrated how air quality impacts labor supply, productivity, and cognition [13]. Isen et al. [14], for instance, found that a higher pollution level in the year of birth is associated with lower labor force participation and lower earnings by age 30. These outcomes can also impact teacher and school performance.

The factors of environmental inequality are also associated with increased all-cause mortality and respiratory morbidity, including exacerbations of asthma, COPD, bronchitis, pneumonia, and cardiovascular conditions, creating an unequal starting point from birth [15-20]. The impacts of this exposure, however, go well beyond simple health outcomes. Prior research found disparities associated with air quality based on economic standing, language minority status, immigration status, race, and ethnicity [21]. Despite this, it is often assumed that all schools in an urban area are exposed to similar outdoor air quality and that school infrastructure protects children equally to produce similar indoor air quality. To extend our understanding of environmental inequalities in urban settings, our research explores how unequal exposure to indoor and outdoor air pollution (e.g., fine particulate matter $\left.\left(\mathrm{PM}_{2.5}\right)\right)$ impacts indoor air quality among high- and low-income schools in Salt Lake City, UT, USA.

Since indoor air quality is affected by outdoor [22] and indoor sources of pollution, environmental conditions, housing characteristics, and behavioral factors [23], we installed research-grade sensors to observe $\mathrm{PM}_{2.5}$ concentrations in indoor and outdoor settings at two high schools with a range of geographic and demographic compositions, (e.g., elevation, distance to pollution source, minority status, and income level). These data and resulting analysis show that poor air quality may impact school settings and the potential implications with respect to environmental inequality. We expect that the results of this study will invigorate debates about the unequal distribution of air pollution and identify what risks, if any, such factors have on the protective properties of schools.

\section{Materials and Methods}

The two high schools included in this study are both located in SLC, Utah (Figures 1 and 2). The state of Utah is well known for its majestic mountains and natural sites, but the air quality in its urban centers can be exceptionally poor during pollution episodes, especially in the lower elevation areas. According to a 2021 report by the American Lung Association, Salt Lake City is the 12th most polluted city nationwide for ozone pollution and 17th most polluted city in the US for short-term particulate pollution [24]. This dubious standing has many contributing factors. 


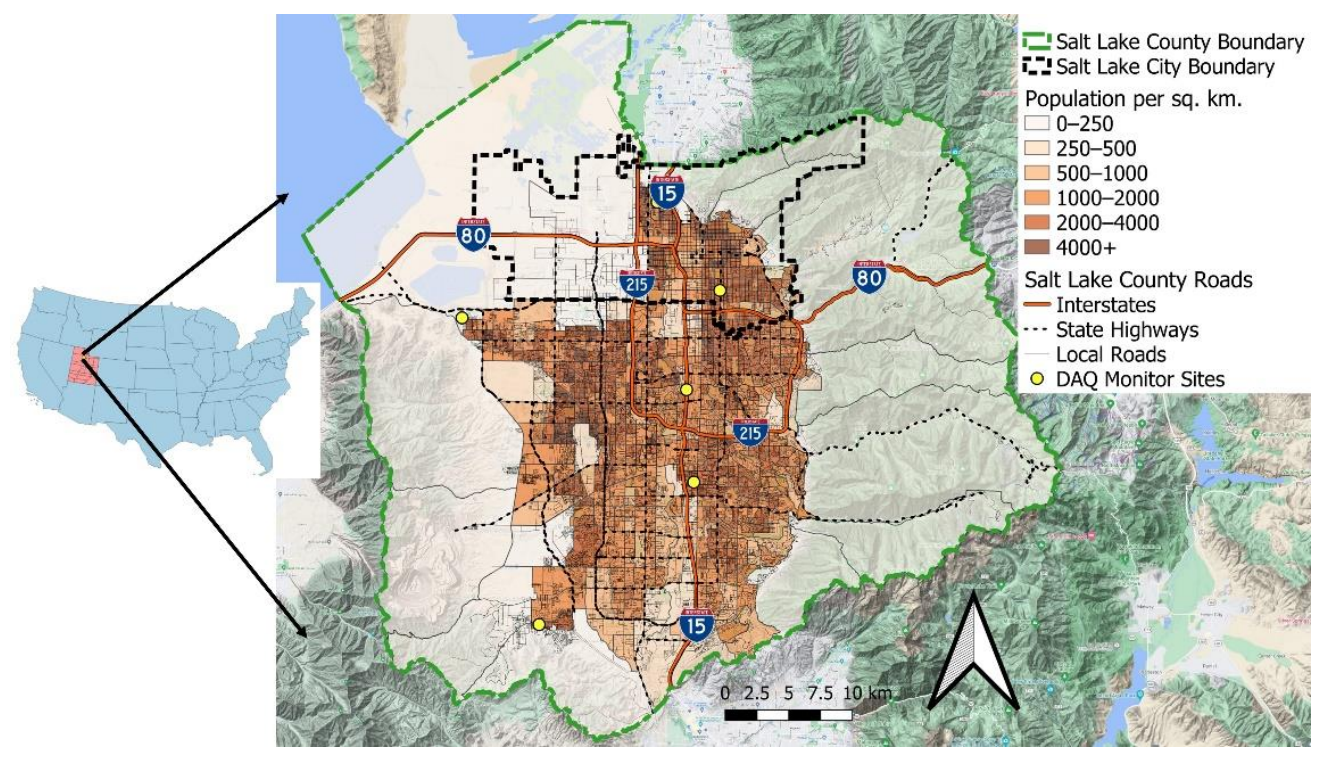

Figure 1. Salt Lake City and Salt Lake County within Utah and the United States (left inset).



Figure 2. Study area showing Salt Lake City's emission sources (2019 tonne $\mathrm{CO}_{2}$ /year), study schools, and regulatory air quality monitoring sites.

As illustrated in Figure 1, SLC is located at the intersection of two major highways (e.g., I-80 and I-15), and therefore, transportation-related emissions are an important contributor to poor air quality. Like many urban areas, traffic density and congestion in Salt Lake County (SLCo) have been increasing by around $10 \%$ or more annually [25], making this and other urban areas increasingly susceptible to transportation-related air pollution. Additionally, SLCo has a unique geography with multiple intersecting high mountain ranges and the Great Salt Lake, surrounding expansive residential housing and a range of heavily polluting industries (Figure 1). The local air pollution problems are further exacerbated by distant and local pollution produced by local and regional dust storms and 
wildfires in the Western United States. As a result, both the summer and winter months are impacted by elevated ozone [26] and $\mathrm{PM}_{2.5}$ [27].

This study deployed research-grade sensors, which are demonstrated to be comparable to regulatory-grade instrumentation in accuracy and precision [28] and significantly more robust and reliable than commonly used low-cost or citizen science sensors [29]. We installed Met One Instruments (Met One Instruments Inc., Grants Pass, OR 97526, USA) ES-642 Remote Dust Monitors, with inlet sharp cut cyclones to measure $\mathrm{PM}_{2.5}$, with the manufacturer's stated uncertainty of $1 \mu \mathrm{g} / \mathrm{m}^{3}$ [30] at schools on opposite sides of SLC. The schools, appropriately named "East High School" (East High) $\left(40.75230^{\circ} \mathrm{N}, 111.85527^{\circ} \mathrm{W}\right.$ [31], Elevation 1373 MASL [32]) and "West High School" (West High) $\left(40.77433^{\circ} \mathrm{N}, 111.90040^{\circ} \mathrm{W}\right.$, Elevation 1302 MASL), are located approximately $4.5 \mathrm{~km}$ apart (Figure 2). At each school (Figure 3), one sensor was located outside the building (East High: south end on roof; West High: northwest corner on roof), and one was inside (East High: northeast corner of East Gym; West High: inside of common area on northwest beam), and each was approximately $3.5 \mathrm{~m}$ aboveground. The western part of SLC, as seen in Figure 2, has a substantial set of emission sources, including two interstate highways, Salt Lake City International Airport, the largest power plant in the city, regional railroad lines, and numerous point sources. The eastern part of SLC is primarily residential and has comparatively smaller roads with few point sources.

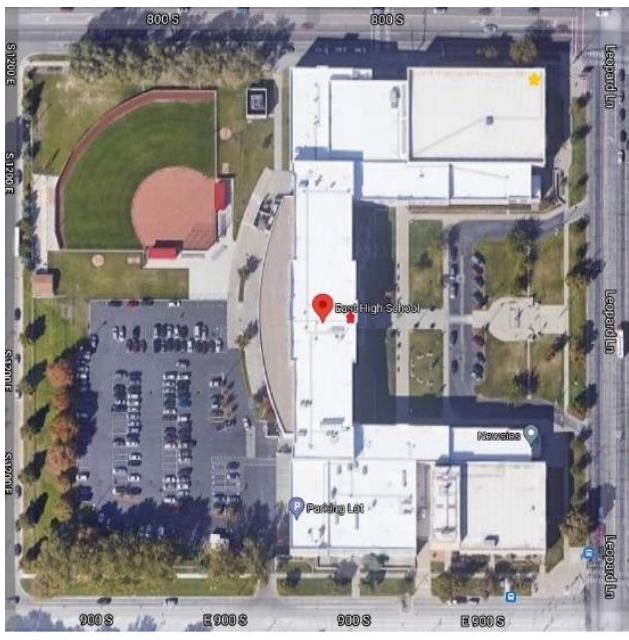

(a)

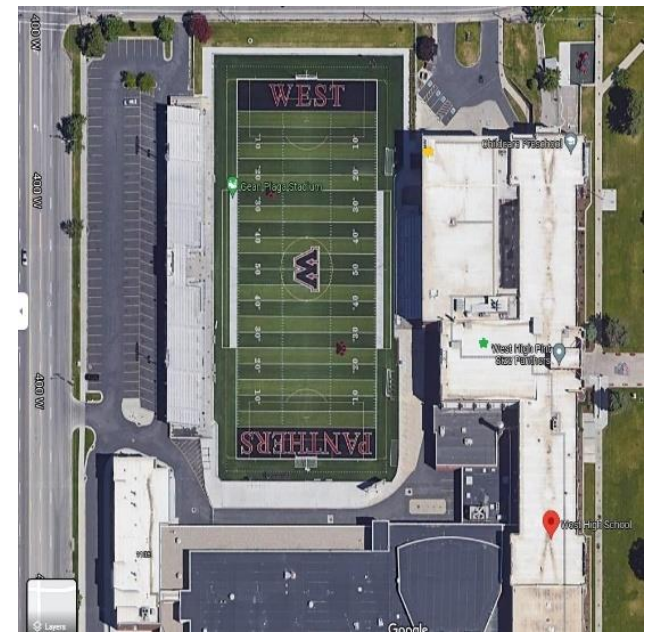

(b)

Figure 3. Study area showing the $\mathrm{PM}_{2.5}$ instrument locations at (a) East High and (b) West High. The locations of the inlets for the indoor sensors are denoted by the yellow stars, while the red symbol denotes the location of the outdoor rooftop sensor.

The study period for this research spanned from 8 February to 30 April 2018. Between November and February each year, SLC experiences periodic temperature inversions, where pollutants accumulate in the stable boundary layer for several days to several weeks [33]. These temperature inversions weaken into spring but are still observed in March for a few days. By April and May, solar insolation is strong enough that generally only nocturnal inversions are noted, and pollution does not build up in the valleys to the extent it does earlier in the year. However, strong winds associated with spring storm systems can bring large dust storms to the region at this time of the year, with April being the dustiest month of the year [34]. The study period in this paper (February-April 2018) is thus representative of both the end of the winter inversion season and the springtime dust season.

The instruments record data at $1 \mathrm{~s}$ intervals, which were later aggregated to average minute and hourly resolutions for $\mathrm{PM}_{2.5}$ concentration, temperature, relative humidity, and pressure. The hourly outdoor readings were compared against regulatory air quality sensor data from the closest Utah Division of Air Quality station (Rose Park and Hawthorne, Figure 2) for each school. The hourly indoor and outdoor readings were compared with 
each other for the duration of the study period. Weekday diurnal cycles were derived for each environment to show the impact of emissions on indoor air quality. Finally, two elevated pollution events (an inversion episode and a dust storm) were studied at $2 \mathrm{~min}$ resolution to understand the rate of pollutant infiltration. To study the infiltration rates of the two pollution types (e.g., inversions and dust), the outdoor reading times were kept fixed, and the indoor readings were lagged from 1 to $180 \mathrm{~min}$ to quantify the most impactful lag period as estimated by the $\mathrm{r}^{2}$ value as further described in Section 3.5.

\section{Results and Discussion}

\subsection{Full Time Series}

The full time series of $\mathrm{PM}_{2.5}$ of both the indoor and outdoor sensors for the full study period is shown in Figure 4. Figure 4a displays the hourly indoor and outdoor $\mathrm{PM}_{2.5}$ readings for East High and the Hawthorne regulatory sensor, while Figure $4 \mathrm{~b}$ presents the indoor and outdoor $\mathrm{PM}_{2.5}$ readings for West High and the Rose Park regulatory sensor. The dashed horizontal lines represent air quality index (AQI) level cutoffs [35]. The associated temperature, relative humidity, and pressure values are found in Appendix A, Figures A1-A6.

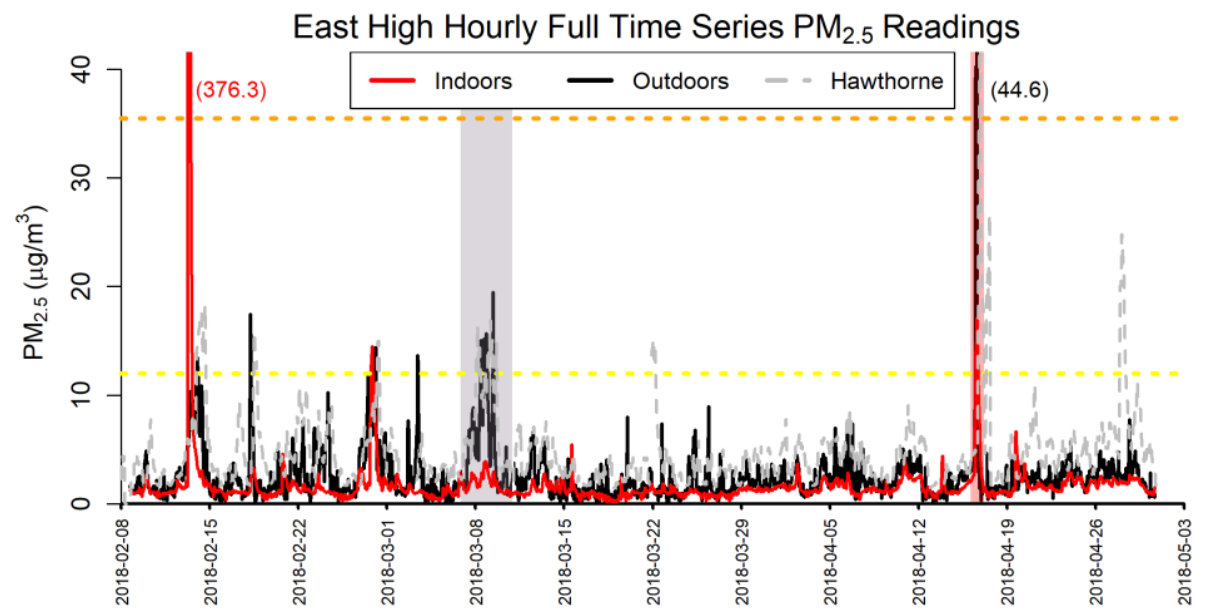

(a)

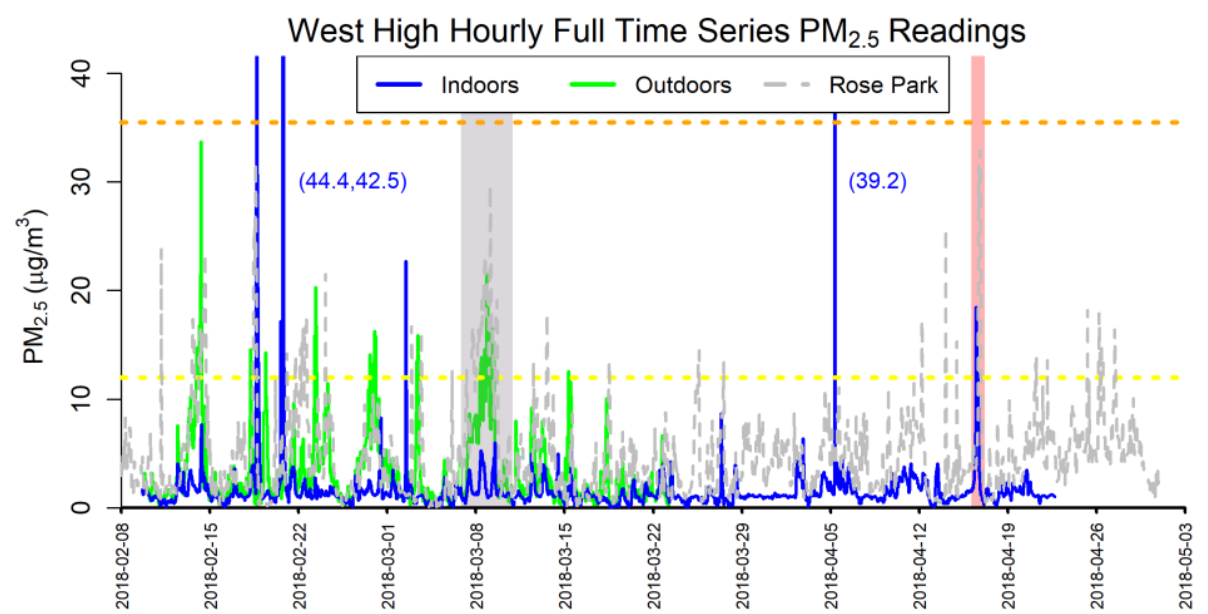

(b)

Figure 4. Hourly full study period time series of $\mathrm{PM}_{2.5}$ readings for (a) East High and (b) West High and the closest regulatory observations. The horizontal lines correspond to AQI levels. The shaded grey and pink time periods denote an atmospheric inversion and a dust storm period. Outlier values are listed next to their occurrence. 
As illustrated in Figure $4 \mathrm{a}, \mathrm{b}, \mathrm{PM}_{2.5}$ readings are generally higher outside than indoors at both East High and West High. West High, being in a higher traffic area, shows on average approximately $25-50 \%$ higher outdoor $\mathrm{PM}_{2.5}$ readings than East High. This demonstrates, for this case study period, the potential environmental inequality impacts. For instance, higher rates of outdoor air quality could lead to lower overall standardized testing scores in low-income schools, even when controlling for other factors (e.g., economic or language status) [6]. It could also lead to higher rates of student absenteeism, which has been shown to impact long-term learning in students [7].

In addition to the averages over the study period, there are three notable anomalies where the $\mathrm{PM}_{2.5}$ concentrations were substantially higher indoors than outdoors. Although we contacted the schools, they were unable to provide explanations for these elevated pollution events. On Tuesday, 13 February, 6:00-9:00 a.m., East High recorded indoor hourly readings of up to $376 \mu \mathrm{g} / \mathrm{m}^{3}$. These values are too high for too long to be the result of instrument failure, which might be indicated by high values for only a few $1 \mathrm{~min}$ observations. As discussed in the Methods section, the instrument was in the gymnasium, and the school buses park and idle outside the door of the gymnasium. As it was a relatively cold day, it is possible that the buses were located close enough to the air intake to directly emit their exhaust, which could then infiltrate the building. It is also possible that vaping activities by students could result in this signal. The prevailing wind during that time was from the southeast; therefore, the outdoor sensor would not have registered the signal as it was upwind from the buses and gymnasium.

The two other indoor spikes occurred on Sunday, 18 February, 5:00-8:00 p.m., and Tuesday, 20 February, 6:00-8:00 p.m. at West High. These elevated events peaked at $71 \mu \mathrm{g} / \mathrm{m}^{3}$ and are consistent with cleaning activity. As the indoor instrument was in the cafeteria and common area, these readings could indicate the effects of vacuuming and kitchen cleaning or cooking activities.

\subsection{School Outdoor vs. Regulatory Sensor PM 2.5}

Figure 5 compares the outdoor data with the nearest regulatory instrument. The regulatory instruments are located approximately 2.5 (East High to Hawthorne) and 3.5 (West High to Rose Park) kilometers from the school. Therefore, their readings are not expected to be wholly representative of the localized school air quality. Both schools generally read lower $\mathrm{PM}_{2.5}$ concentrations than their corresponding regulatory instrument. This is likely due to the location of the schools near lower traffic roads compared with larger roads near the regulatory sensors. As noted in the previous section, the outdoor $\mathrm{PM}_{2.5}$ readings for West High are generally higher than for East High.

\subsection{School Indoor vs. Outdoor $P_{2.5}$ Overview}

The school indoor and outdoor sensor readings are compared in Figure 6. The comparisons are for the available study dates for each site on 8 February-30 April for East High and 9 February-22 March for West High. We performed analysis using data from 9 February to $22 \mathrm{March}$, and the results for East High did not vary enough to warrant exclusion. The indoor readings are generally lower than the outdoor readings, and the slope is higher for East High than West High, indicating generally proportionately lower concentrations of $\mathrm{PM}_{2.5}$ observed indoors at West High relative to East High compared with the outside readings. The indoor $\mathrm{PM}_{2.5}$ readings are generally consistent across both schools, and the slope difference is attributable to the higher outdoor concentrations observed at West High since the indoor readings are similar across both schools. When evaluated more closely, interesting variations between indoor and outdoor $\mathrm{PM}_{2.5}$ concentrations are observed as a function of time (Section 3.4). Diurnal cycles and type of pollutant episode (winter inversion vs. dust event) are discussed in the next section. 


\section{School Outdoor vs. DAQ PM 2.5}

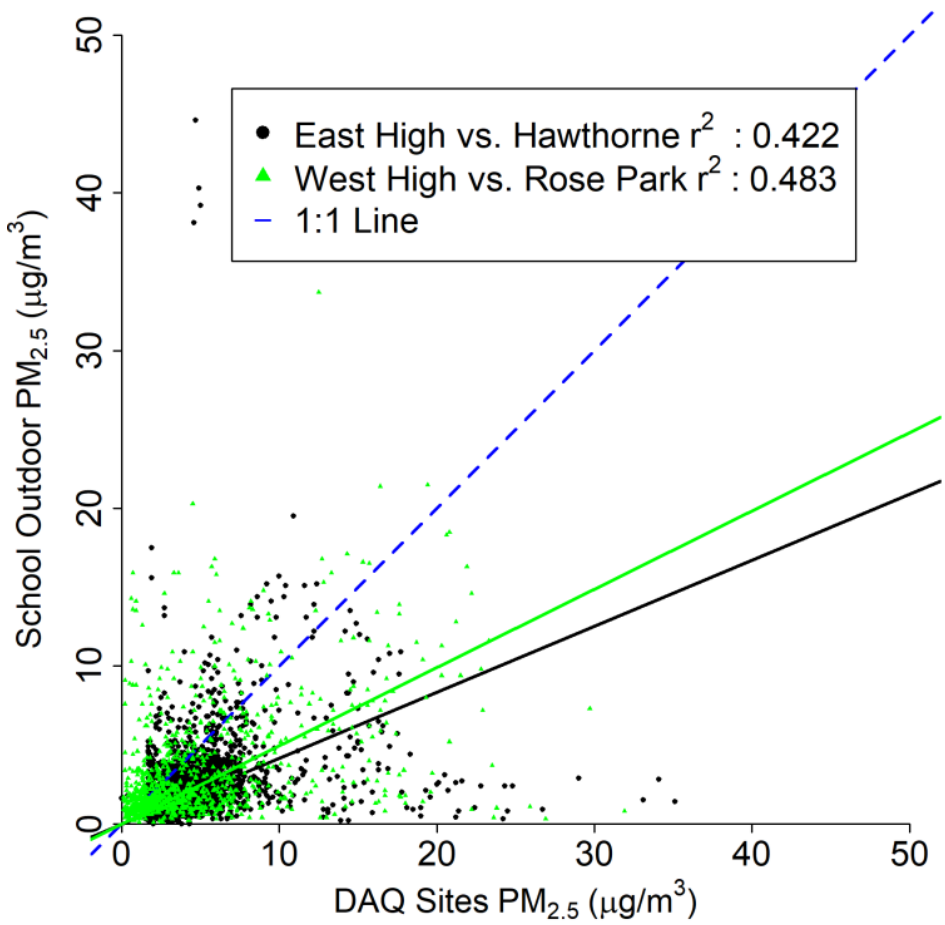

Figure 5. School outdoor sensor readings compared with the nearest regulatory sensor.

\section{School Indoor vs. Outdoor $\mathrm{PM}_{2.5}$}

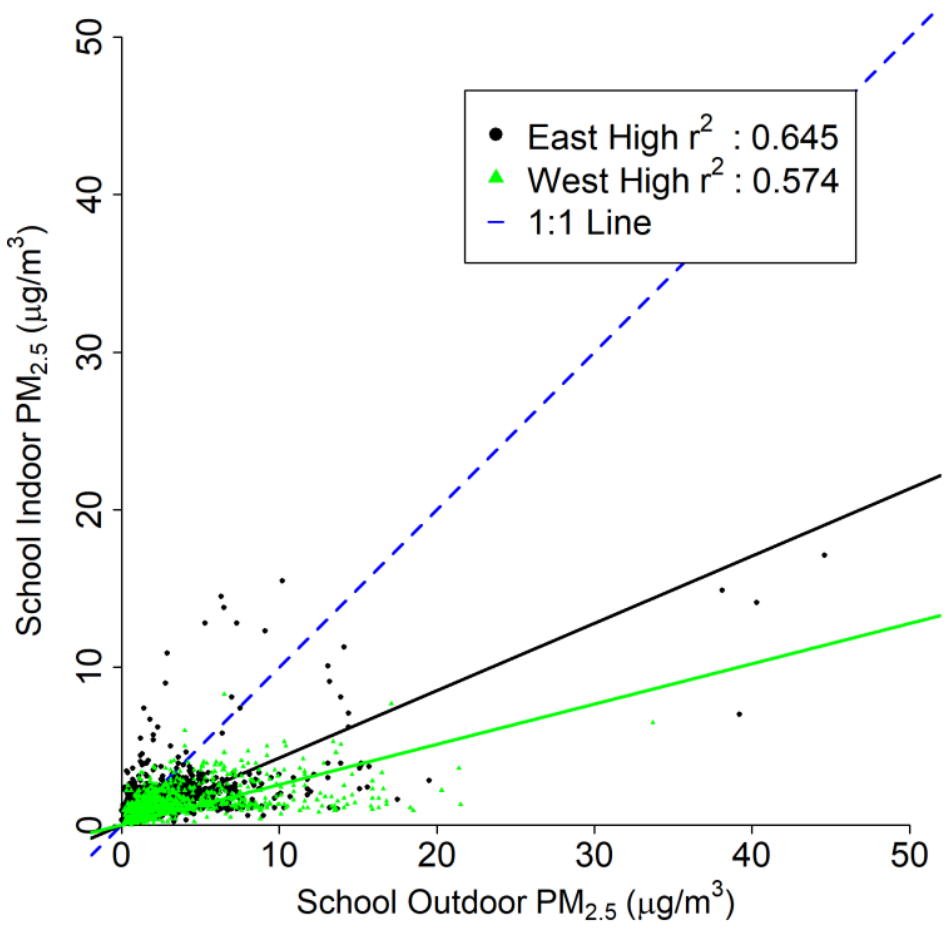

Figure 6. School indoor vs. outdoor $\mathrm{PM}_{2.5}$ sensor reading.

\subsection{School Indoor vs. Outdoor $P_{2.5}$ and Weekday Diurnal Cycle}

The weekday diurnal cycle $\mathrm{PM}_{2.5}$ concentrations and outdoor/indoor ratio at the four sites are shown in Figure 7. The diurnal cycle is highlighted by the rapid increase 
in the early morning hours due to the morning rush hour vehicular emissions and combustion activity from commercial and industrial buildings (Figure 7a). Additionally, the atmospheric boundary layer is lowest in the early morning hours. As the day progresses, $\mathrm{PM}_{2.5}$ becomes more well mixed in the atmosphere, leading to a decline in the outdoor concentration. There is a notable lag in the concentration readings for the indoor instruments compared with the outside ones. This is likely due to building infiltration rates and contamination from indoor sources (Figure $7 \mathrm{~b}$ ).

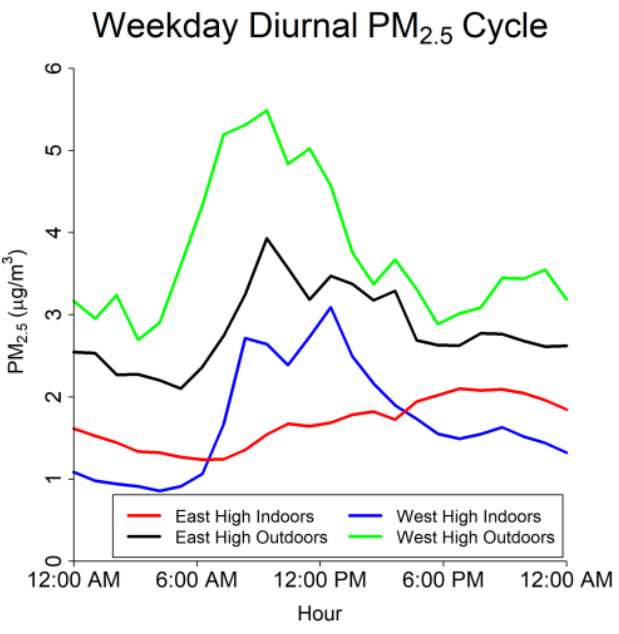

(a)

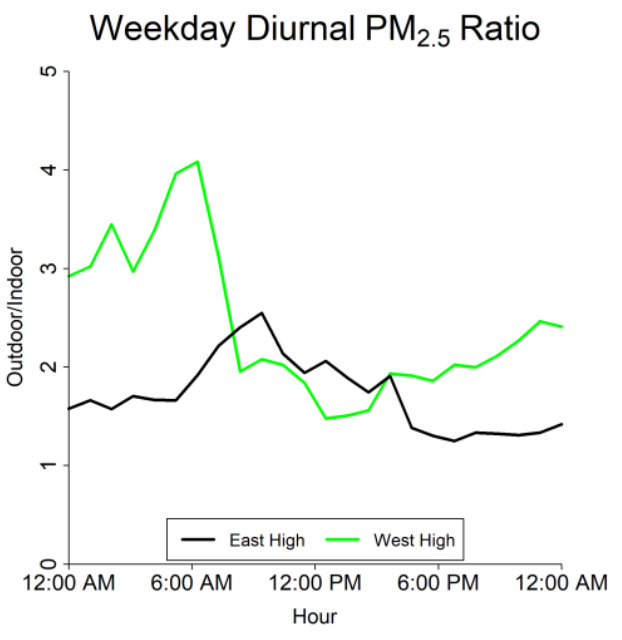

(b)

Figure 7. Weekday diurnal cycle (a) and diurnal $\mathrm{PM}_{2.5}$ outdoor/indoor ratio (b) for study schools.

\subsection{Pollutant Accumulation from 7 to 9 March-Atmospheric Inversion Event}

A multiday pollution accumulation event due to a weak inversion episode [27] is shown in Figure 8. As discussed in the previous section, there appeared to be a lag between elevated $\mathrm{PM}_{2.5}$ inside compared with outside of schools. To capture the potential range of possible lags, the minute-resolved indoor data were lagged with respect to the outdoor readings by 1 to $180 \mathrm{~min}$. The best fit was determined as the lag that produced the highest $r^{2}$ value.

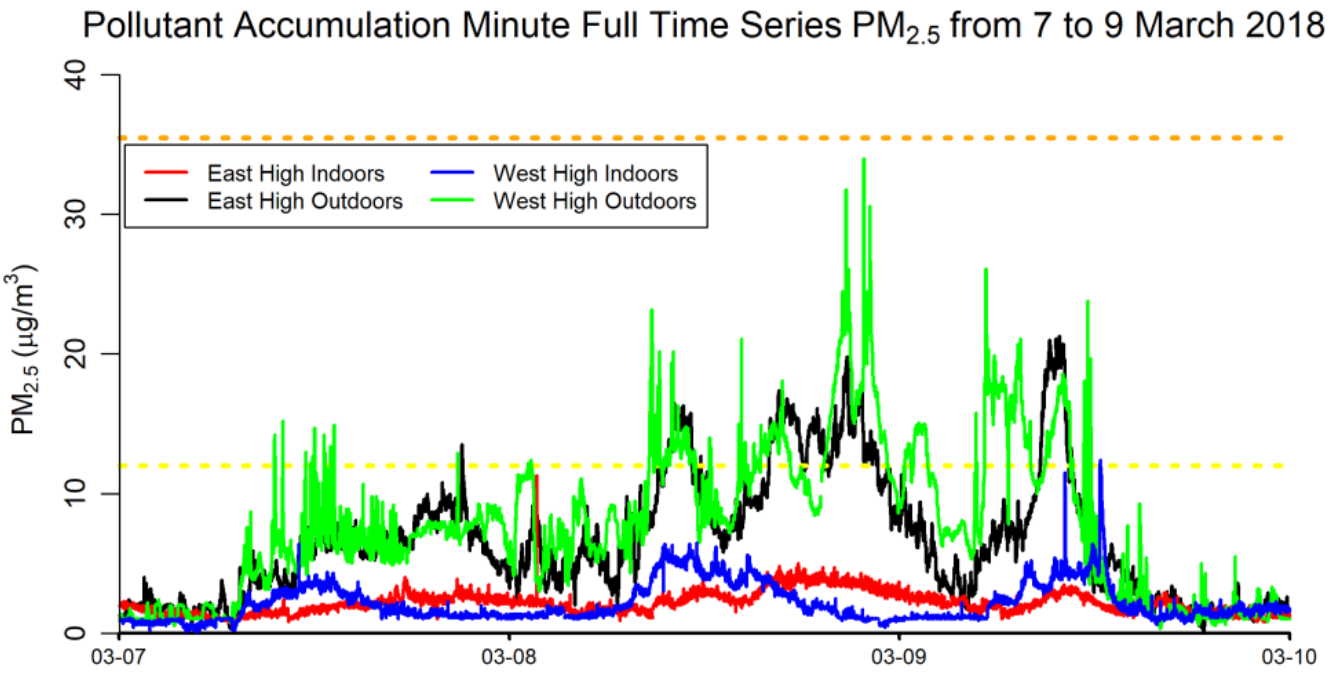

Figure 8. Pollution accumulation event from 7 to 9 March 2018.

The coefficient of determination comparing lagged indoor measurements and outdoor measurement and the comparison between the lagged values are shown in Figure 9. The 
highest $\mathrm{r}^{2}$ value (0.878) for East High was at a lag of $57 \mathrm{~min}$ (Figure 9a,b). West High had its highest $\mathrm{r}^{2}$ value (0.646) at a lag of $35 \mathrm{~min}$, but there was another similar peak at $135 \mathrm{~min}$ (Figure 9c,d). However, the variability in the $\mathrm{r}^{2}$ value was minimal between minutes 35 and 135. A potential explanation for the difference in lag values between the two schools is the air handling activity.

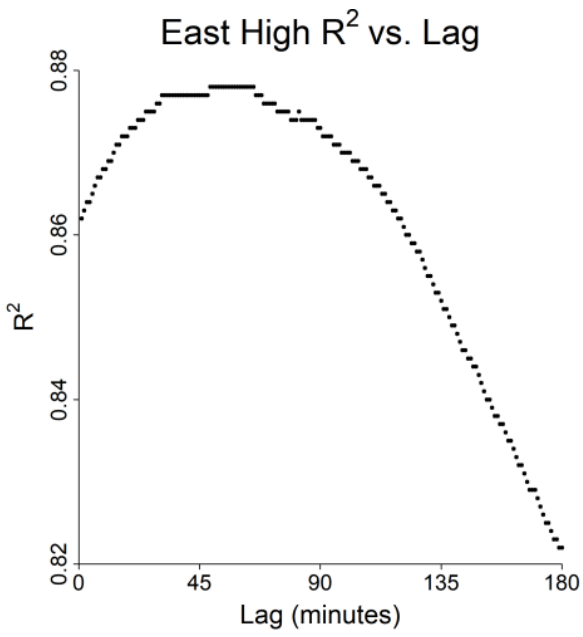

(a)

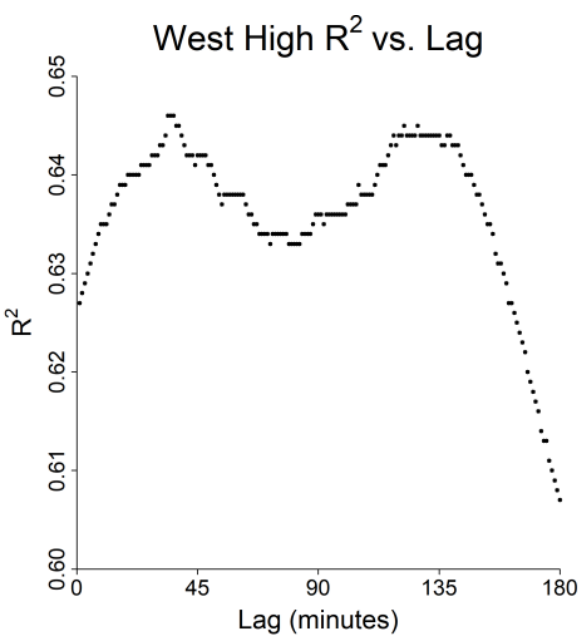

(c)



(b)

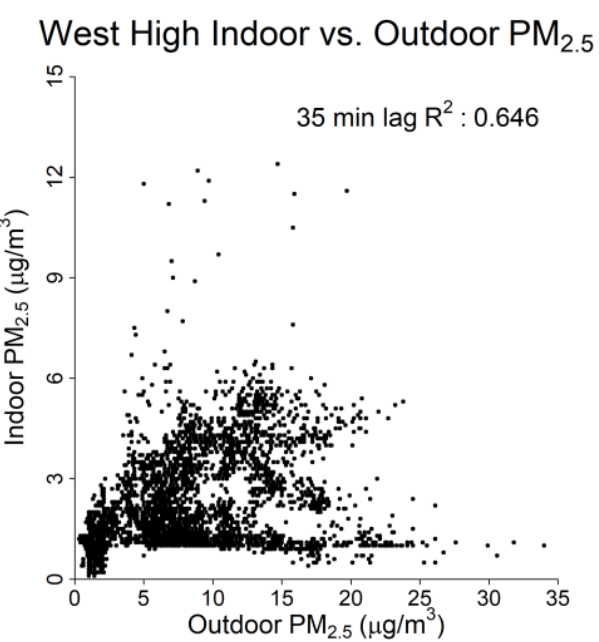

(d)

Figure 9. Coefficient of determination and comparison between lagged indoor and outdoor $\mathrm{PM}_{2.5}$ readings at the highest coefficient of determination: (a) coefficient of determination for East High, (b) East High 57 min lagged indoor and outdoor $\mathrm{PM}_{2.5}$, (c) coefficient of determination for West High, and (d) West High 35 min lagged indoor and outdoor $\mathrm{PM}_{2.5}$.

Table 1 lists the meteorological conditions, both indoor and outdoor, during the elevated pollution event for both sites. The $\mathrm{PM}_{2.5}$ difference between the indoor and outdoor concentrations is nearly $25 \%$ larger at West High compared with East High. While the outdoor temperature is similar at both schools, the indoor temperature is over $4{ }^{\circ} \mathrm{C}$ higher at West High, and the standard deviation is nearly twice that of East High. The mean and standard deviation of the indoor relative humidity at both schools are nearly identical, with a similar pattern for the pressure. Therefore, the indoor temperature is associated with the indoor $\mathrm{PM}_{2.5}$ readings. 
Table 1. Meteorological conditions during elevated pollution event.

\begin{tabular}{cccc}
\hline Study Site & Metric & Mean & Standard Deviation \\
\hline \multirow{5}{*}{ East High Indoors } & $\mathrm{PM}_{2.5}\left(\mu \mathrm{g} / \mathrm{m}^{3}\right)$ & 1.84 & 0.83 \\
& Temperature $\left({ }^{\circ} \mathrm{C}\right)$ & 22.01 & 0.49 \\
& Relative Humidity $(\%)$ & 15.60 & 1.53 \\
& Pressure $(\mathrm{mbar})$ & 866.12 & 4.56 \\
\hline \multirow{5}{*}{ East High Outdoors } & $\mathrm{PM}_{2.5}\left(\mu \mathrm{g} / \mathrm{m}^{3}\right)$ & 4.89 & 4.30 \\
& Temperature $\left({ }^{\circ} \mathrm{C}\right)$ & 6.58 & 8.27 \\
& Relative Humidity $(\%)$ & 29.92 & 10.49 \\
& Pressure $(\mathrm{mbar})$ & 864.65 & 4.45 \\
\hline \multirow{3}{*}{ West High Indoors } & $\operatorname{PM}_{2.5}\left(\mu \mathrm{g} / \mathrm{m}^{3}\right)$ & 1.79 & 1.26 \\
& Temperature $\left({ }^{\circ} \mathrm{C}\right)$ & 26.02 & 0.93 \\
& Relative Humidity $(\%)$ & 14.15 & 1.49 \\
& Pressure $(\mathrm{mbar})$ & 874.12 & 4.69 \\
\hline \multirow{3}{*}{ West High Outdoors } & PM $2.5\left(\mu \mathrm{\mu} / \mathrm{m}^{3}\right)$ & 5.61 & 5.19 \\
& Temperature $\left({ }^{\circ} \mathrm{C}\right)$ & 6.61 & 6.35 \\
& Relative Humidity $(\%)$ & 21.90 & 7.33 \\
\hline
\end{tabular}

Inversions, such as the case highlighted in this section, are composed of mostly $(70 \%+)$ secondary pollutants, which dissipate indoors due to the changing ambient conditions (e.g., warmer temperatures and lower relative humidity). As will be shown in the next section, the indoor school environment during these inversion episodes is more protective against the secondary pollutants, following a short lag, than during other situations, such as the dust storm highlighted next.

\subsection{Dust Event on 16 April}

The resulting indoor and outdoor $\mathrm{PM}_{2.5}$ measurements during a dust storm is shown in Figure 10. Only East High had both sensors available during this event as the outdoor sensor at West High was not operational during this event.

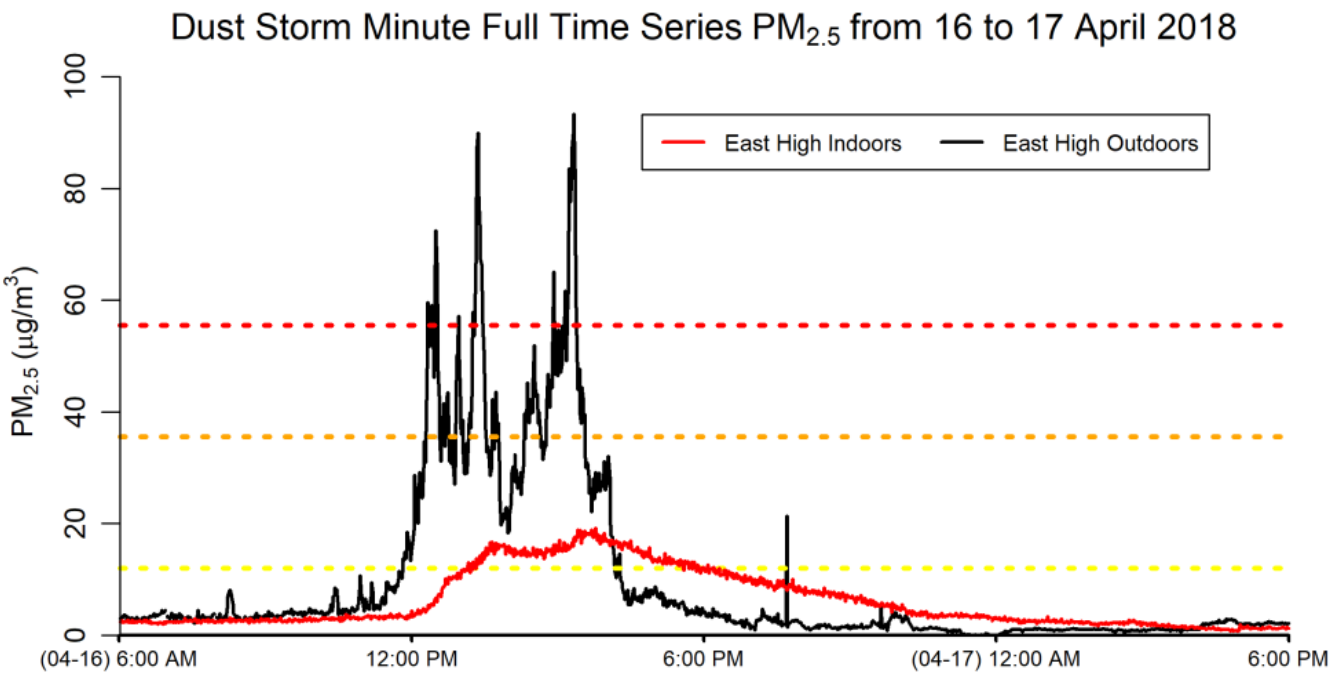

Figure 10. Dust storm event from 16 to 17 April 2018.

The coefficient of determination comparing lagged indoor measurements and outdoor measurement and the comparison between the lagged values are shown in Figure 11. An interesting feature is the shape of the distribution compared with the near-linear relationship found in Figure 6. At concentrations below $10 \mu \mathrm{g} / \mathrm{m}^{3}$, the relationship is relatively linear, but at higher concentrations, there is a substantial slope change. This may 
be explained by the filtration system used in the school. Unlike the March event, which was mainly attributable to secondary particulate matter from an inversion event, the April dust event was composed of primary windblown particulate matter (these dust particles would also be likely larger on average than during the earlier event). Therefore, the building air handling system was involved in filtering the $\mathrm{PM}_{2.5}$ as outside air was brought into the building. It seems that when the efficiency limit was reached, it led to indoor $\mathrm{PM}_{2.5}$ readings of $20 \mu \mathrm{g} / \mathrm{m}^{3}$ or below regardless of the outside readings. It is also possible that the larger particles settled or deposited more associated with the dust storm [36] during which most of the observation above $30 \mu \mathrm{g} / \mathrm{m}^{3}$ occurred. Furthermore, the lag (73 min) is comparable to the lag found in the previous section $(57 \mathrm{~min})$ for East High.

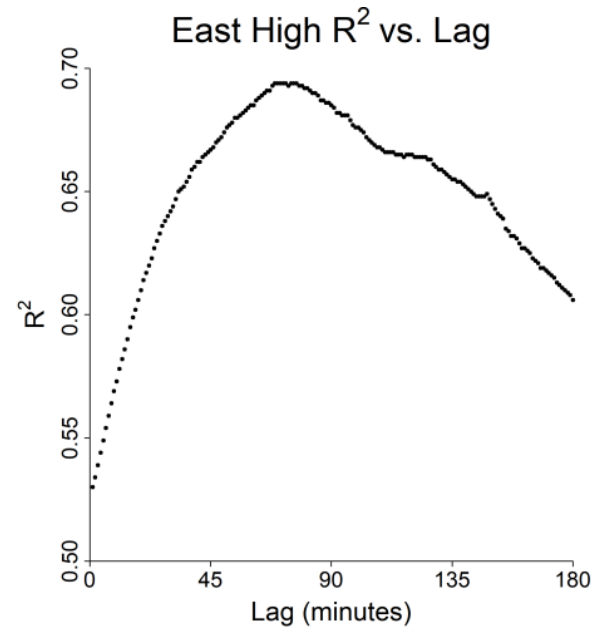

(a)

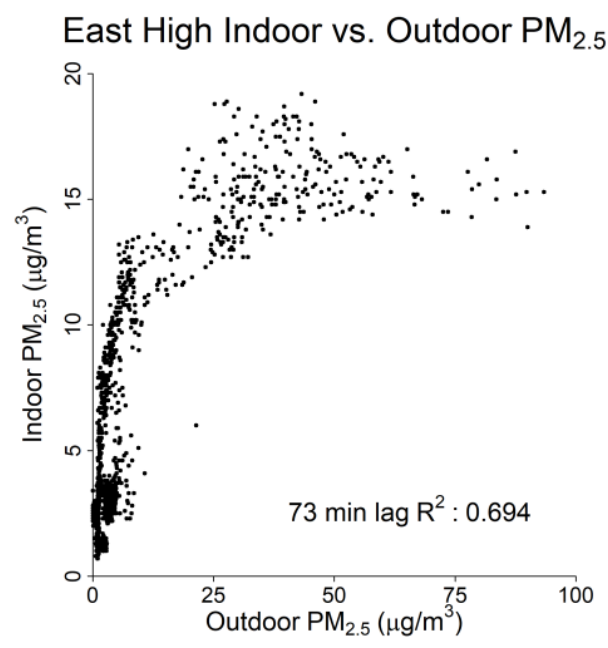

(b)

Figure 11. Coefficient of determination and comparison between lagged indoor and outdoor $\mathrm{PM}_{2.5}$ readings at the highest coefficient of determination: (a) coefficient of determination for East High; (b) East High 73 min lagged indoor and outdoor $\mathrm{PM}_{2.5}$.

\section{Conclusions}

\subsection{Implications}

This research sought to understand how environmental inequality impacts schools in Salt Lake City, Utah. Outdoor sited sensors at both high schools produced similar results to regulatory sensors, suggesting that research-grade sensors are useful for providing protective information for schools-especially when used in low-income communities where infrastructure might be older. As Utah school-aged children spend at least $900 \mathrm{~h}$ a year inside schools, it is imperative to quantify and understand the potential protectiveness of these buildings. Furthermore, schools are often gathering spaces and provide recreational opportunities during off-school hours, especially in lower-income and rural communities.

In this study, we found that inversions were composed of mostly $(70 \%+)$ secondary pollutants, which dissipated indoors due to the changing ambient conditions (e.g., warmer temperatures and lower relative humidity). As a result, schools were shown to be more protective against the secondary pollutants that dominate inversion episodes, following a short lag, than during other situations. What remains concerning is that outdoor air during other pollution events has not been found to behave this way [22]. Since we found notable differences in outdoor air quality between the two schools, this may be a source of concern for other elevated pollution events, such as wildfires. Deng and Lau [37] also found temperature and humidity to be correlated to indoor air quality, and the relationship was consequential for the resulting particle count in their study on $\mathrm{CO}_{2}$. They also found large seasonal variations in humidity level, ventilation rate, particle counts, and formaldehyde concentration. It was, therefore, suggested that the monitoring of classroom indoor air 
quality (IAQ) and thermal comfort (TC) should be performed periodically across the whole school year to comprehensively describe the conditions.

This study compared indoor and outdoor $\mathrm{PM}_{2.5}$ readings at high- and low-income schools located in different parts of Salt Lake City, Utah, a rapidly growing urban community. It was found that there was a lag ranging between 35 and 73 min for the outdoor $\mathrm{PM}_{2.5}$ concentrations to follow a similar temporal pattern as the indoor $\mathrm{PM}_{2.5}$. This lag has policy and health implications and may help to explain rising concerns regarding reduced educational outcomes related to air pollution in urban areas. Interventions could be created to narrow this unhealthy period in the lag, and supplementary equipment could be used to offset the lag during atmospheric inversion events as well as dust events. This raises the question of what the lag means for COVID-19 conditions, where drawing air in is essential for protecting students from COVID-19, but more of that air is harmful for other reasons. Resolving this dilemma is especially important in lower-income communities, where other situational factors may compound these outcomes over the long term.

\subsection{Future Work}

This study provides a preliminary framework for evaluating environmental inequality in two high schools (East High, a high-income school, and West High, a low-income school) in Salt Lake City, Utah. While higher levels of outdoor pollutants were observed at the low-income school (e.g., West High), more research is needed to understand why indoor pollutants were lower, potentially providing some good news with respect to environmental inequality at West High school. The differences in outdoor and indoor particulate pollutants found in this study at the two high schools warrant future research to better understand some of the driving factors over multiple seasons and a larger range of pollutant types (e.g., ozone, $\mathrm{NO}_{2}, \mathrm{CO}_{2}$ ) and concentrations. For example, do differences in air intake and filtration systems, chemical properties, and size of outdoor pollutants (e.g., primary vs. secondary particulates) or outdoor humidity levels impact the indoor pollutant concentrations? Additionally, how much do the indoor particulate pollutants vary between different locales in the same school? In this study, the indoor sensors were placed in the cafeteria and gymnasium by necessity. Future studies could focus on observing those indoor locations that were most visited by students (individual classrooms).

In addition, future research could include comonitoring the differences in indoor and outdoor pollution for additional criteria pollutants, such as ozone or nitrogen dioxide. For example, in airtight buildings ozone can be lower than outside, whereas in poorly sealed buildings it can be higher than outside [38].

To account for larger particle sizes and the lag, future studies could resolve the indoor particle components and compare them with the event type (e.g., inversions, dust storms, and wildfires). Future studies could also compare the filtration system of the schools and make some recommendations to account for different lag events in the light of confounding factors (e.g., COVID-19). Furthermore, the impact of the use of fine filters, such as F8 (MERV14) filter, on indoor air quality merits additional research.

Author Contributions: Conceptualization, B.F., C.A., D.L.M., R.B. and S.A.G.; methodology, B.F., C.A., D.L.M., E.T.C., R.B., S.A.G., S.H. and T.M.B.; software, B.F., C.A., D.L.M., R.B. and S.A.G.; validation, B.F., C.A., D.L.M., E.T.C., R.B., S.A.G., S.H. and T.M.B.; formal analysis, B.F., C.A., D.L.M., E.T.C., R.B., S.A.G., S.H. and T.M.B.; investigation, B.F., C.A., D.L.M., E.T.C., R.B., S.A.G., S.H. and T.M.B.; resources, B.F., C.A., D.L.M., R.B. and S.A.G.; data curation, B.F., C.A., D.L.M., R.B. and S.A.G.; writing-original draft preparation, B.F., C.A., D.L.M., E.T.C., R.B., S.A.G., S.H. and T.M.B.; writing-review and editing, B.F., C.A., D.L.M., E.T.C., R.B., S.A.G., S.H. and T.M.B.; visualization, D.L.M.; supervision, B.F., C.A., D.L.M., E.T.C., R.B., S.A.G., S.H. and T.M.B.; project administration, B.F., C.A., R.B. and S.A.G.; funding acquisition, B.F., C.A., D.L.M., R.B. and S.A.G. All authors have read and agreed to the published version of the manuscript.

Funding: This research was funded by the Salt Lake County Health Department. Equipment and support staff were provided by the Salt Lake County Health Department and the University of Utah. 
Institutional Review Board Statement: Not applicable.

Informed Consent Statement: Not applicable.

Data Availability Statement: The data presented in this study are available on request from the corresponding author. The data are not publicly available due to this section due to school privacy concerns.

Acknowledgments: Charles Snow, technical assistant on this project.

Conflicts of Interest: The authors declare no conflict of interest.

\section{Appendix A}

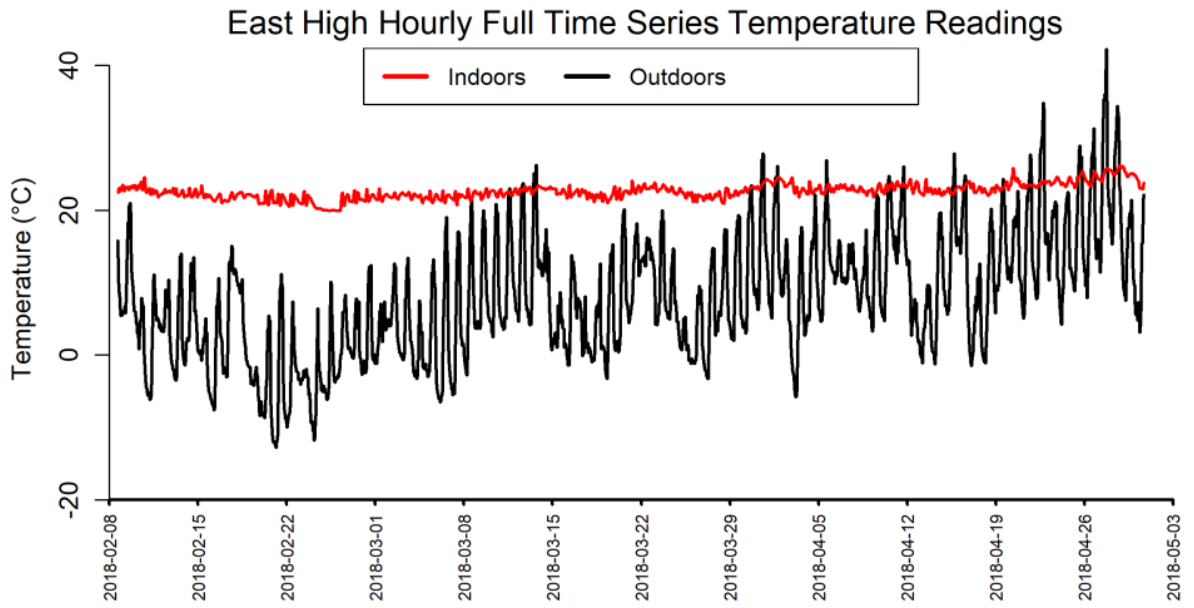

Figure A1. Indoor and outdoor temperature at East High.

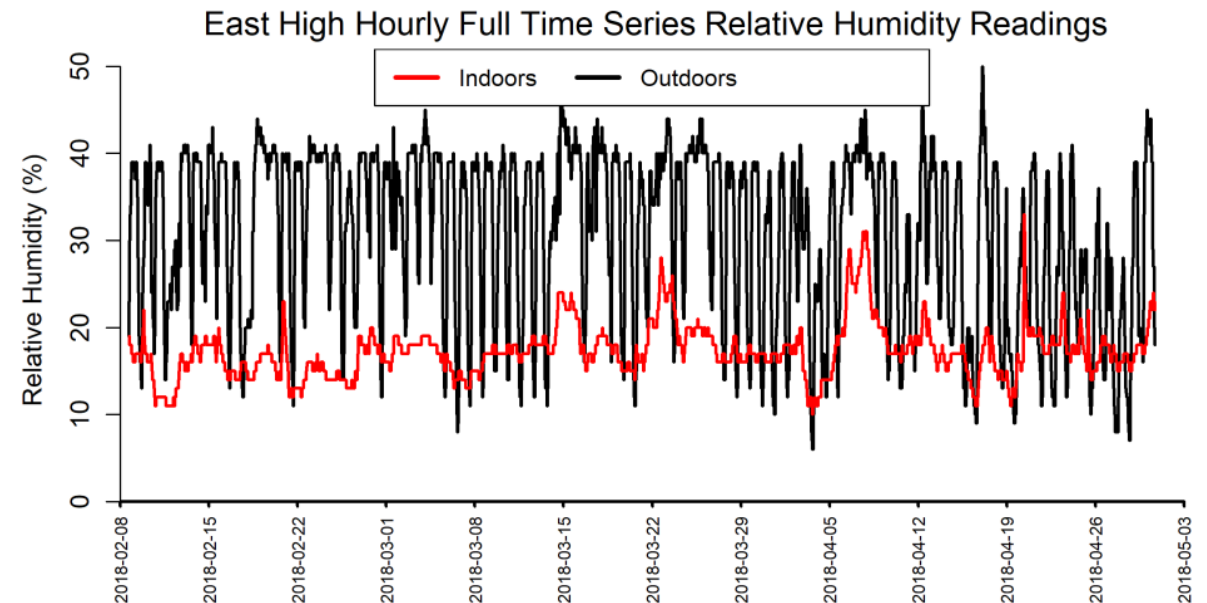

Figure A2. Indoor and outdoor relative humidity at East High. 


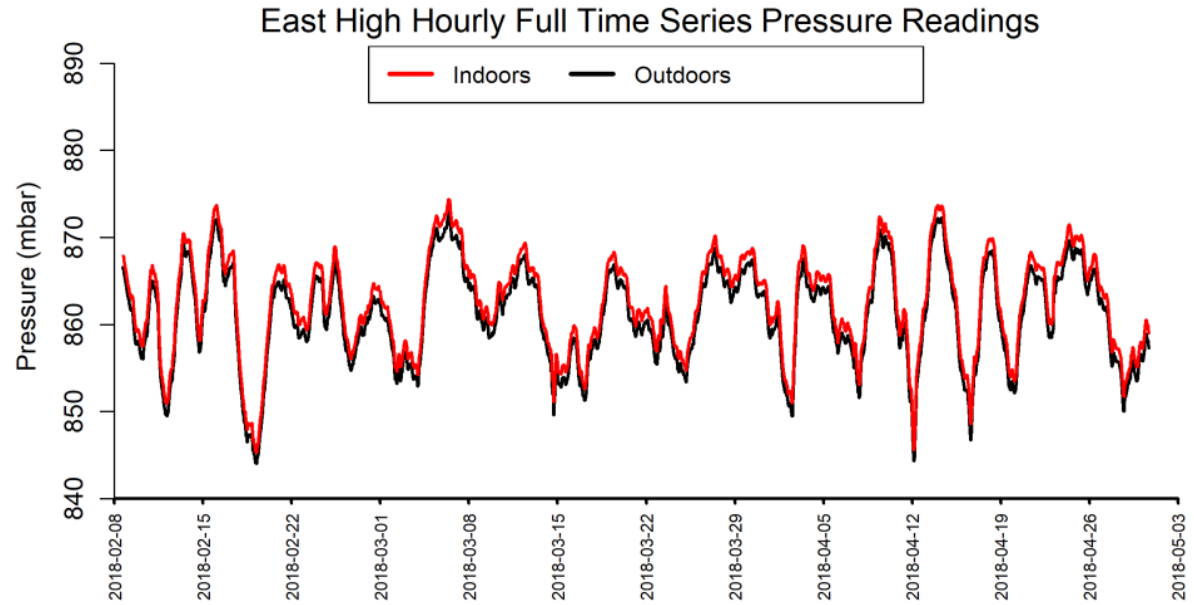

Figure A3. Indoor and outdoor atmospheric pressure at East High.

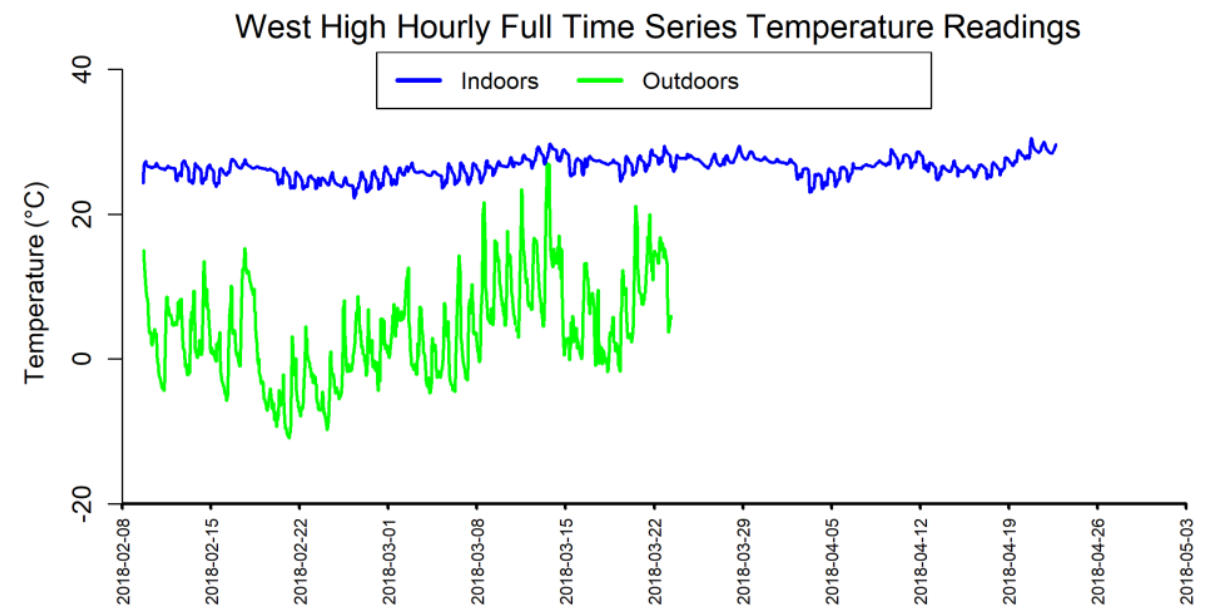

Figure A4. Indoor and outdoor temperature at West High.

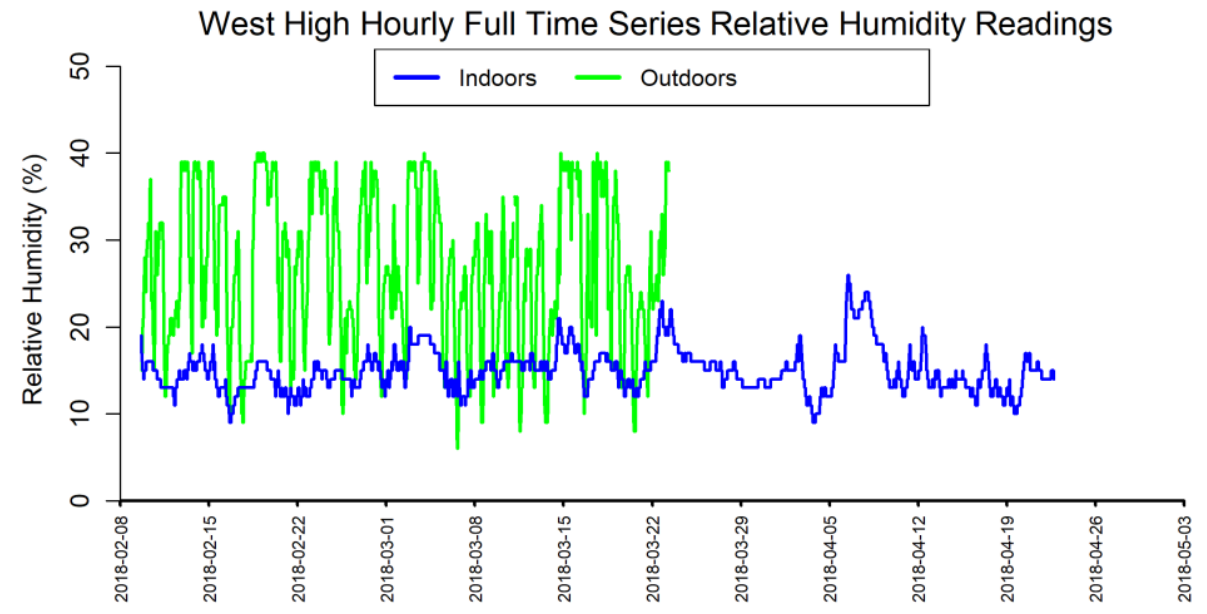

Figure A5. Indoor and outdoor relative humidity at West High. 


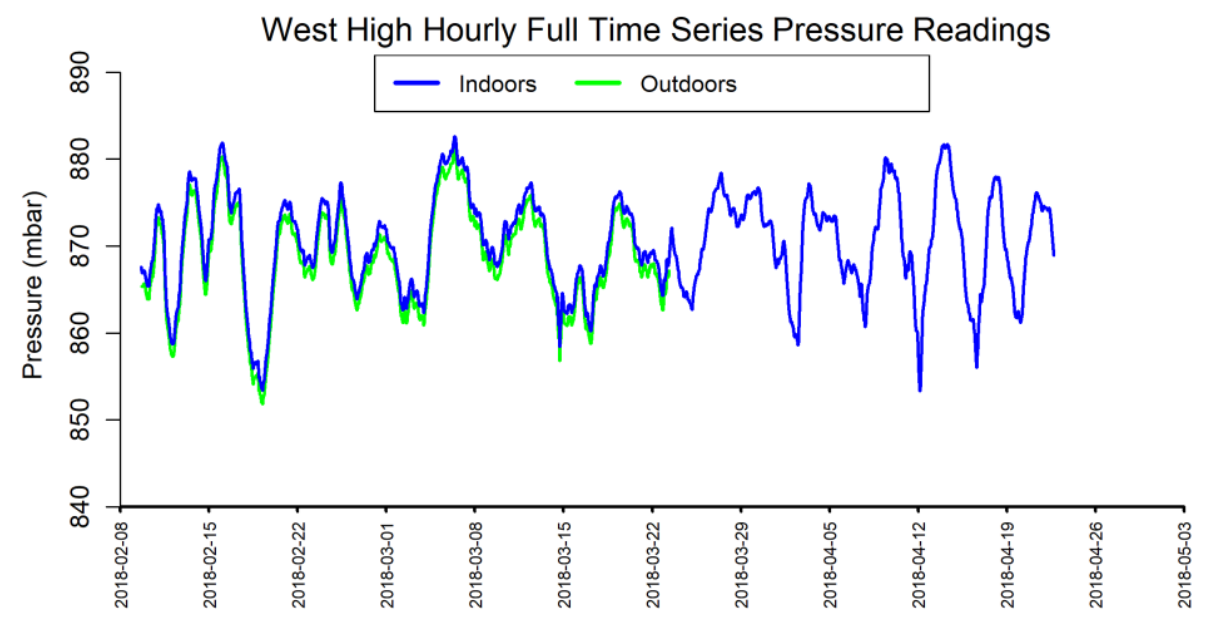

Figure A6. Indoor and outdoor atmospheric pressure at West High.

\section{References}

1. WHO. Air Pollution And Child Health: Prescribing Clean Air; World Health Organization: Geneva, Switzerland, 2018.

2. Gassebner, M.; Lamla, M.J.; Sturm, J.-E. Determinants of pollution: What do we really know? Oxf. Econ. Pap. 2011, 63, 568-595. [CrossRef] [PubMed]

3. Hajat, A.; Hsia, C.; O’Neill, M.S. Socioeconomic Disparities and Air Pollution Exposure: A Global Review. Curr. Environ. Health Rep. 2015, 2, 440-450. [CrossRef] [PubMed]

4. Clark, L.P.; Millet, D.B.; Marshall, J.D. National patterns in environmental injustice and inequality: Outdoor $\mathrm{NO}_{2}$ air pollution in the United States. PLoS ONE 2014, 9, e94431. [CrossRef]

5. Miller, S.; Vela, M. The Effects of Air Pollution on Educational Outcomes: Evidence from Chile; Inter-American Development Bank (IDB): Washington, DC, USA, 2013.

6. Mullen, C.; Grineski, S.E.; Collins, T.W.; Mendoza, D.L. Effects of $\mathrm{PM}_{2.5}$ on Third Grade Students' Proficiency in Math and English Language Arts. Int. J. Environ. Res. Public Health 2020, 17, 6931. [CrossRef]

7. Mendoza, D.L.; Pirozzi, C.S.; Crosman, E.T.; Liou, T.G.; Zhang, Y.; Cleeves, J.J.; Bannister, S.C.; Anderegg, W.R.L.; Robert, P.I Impact of low-level fine particulate matter and ozone exposure on absences in K-12 students and economic consequences. Environ. Res. Lett. 2020, 15, 114052. [CrossRef]

8. $\quad$ Errigo, I.M.; Abbott, B.W.; Mendoza, D.L.; Mitchell, L.; Sayedi, S.S.; Glenn, J.; Kelly, K.E.; Beard, J.D.; Bratsman, S.; Carter, T.; et al. Human Health and Economic Costs of Air Pollution in Utah: An Expert Assessment. Atmosphere 2020, 11, 1238. [CrossRef]

9. Landrigan, P.J.; Rauh, V.A.; Galvez, M.P. Environmental justice and the health of children. Mt. Sinai J. Med. J. Transl. Pers. Med. 2010, 77, 178-187. [CrossRef]

10. Currie, J. Inequality at birth: Some causes and consequences. Am. Econ. Rev. 2011, 101, 1-22. [CrossRef]

11. Sanders, N.J. What doesn't kill you makes you weaker: Prenatal pollution exposure and educational outcomes. J. Hum. Resour. 2012, 47, 826-850. [CrossRef]

12. Currie, J.; Zivin, J.G.; Mullins, J.; Neidell, M. What do we know about short-and long-term effects of early-life exposure to pollution? Annu. Rev. Resour. Econ. 2014, 6, 217-247. [CrossRef]

13. Graff Zivin, J.; Neidell, M. Environment, health, and human capital. J. Econ. Lit. 2013, 51, 689-730. [CrossRef]

14. Isen, A.; Rossin-Slater, M.; Walker, W.R. Every breath you take-Every dollar you'll make: The long-term consequences of the clean air act of 1970. J. Political Econ. 2017, 125, 848-902. [CrossRef]

15. Brauer, M. How much, how long, what, and where: Air pollution exposure assessment for epidemiologic studies of respiratory disease. Proc. Am. Thorac. Soc. 2010, 7, 111-115. [CrossRef] [PubMed]

16. DeVries, R.; Kriebel, D.; Sama, S. Outdoor air pollution and COPD-related emergency department visits, hospital admissions, and mortality: A meta-analysis. COPD J. Chronic Obstr. Pulm. Dis. 2017, 14, 113-121. [CrossRef]

17. McCreanor, J.; Cullinan, P.; Nieuwenhuijsen, M.J.; Stewart-Evans, J.; Malliarou, E.; Jarup, L.; Harrington, R.; Svartengren, M.; Han, I.-K.; Ohman-Strickland, P.; et al. Respiratory effects of exposure to diesel traffic in persons with asthma. N. Engl. J. Med. 2007, 357, 2348-2358. [CrossRef]

18. Zanobetti, A.; Schwartz, J. The effect of fine and coarse particulate air pollution on mortality: A national analysis. Environ. Health Perspect. 2009, 117, 898-903. [CrossRef]

19. Liu, L.; Poon, R.; Chen, L.; Frescura, A.-M.; Montuschi, P.; Ciabattoni, G.; Wheeler, A.; Dales, R. Acute effects of air pollution on pulmonary function, airway inflammation, and oxidative stress in asthmatic children. Environ. Health Perspect. 2009, 117, 668-674. [CrossRef] 
20. Santana, J.C.C.; Miranda, A.C.; Souza, L.; Yamamura, C.L.K.; Coelho, D.d.F.; Tambourgi, E.B.; Berssaneti, F.T.; Ho, L.L. Clean production of biofuel from waste cooking oil to reduce emissions, fuel cost, and respiratory disease hospitalizations. Sustainability 2021, 13, 9185. [CrossRef]

21. García, E.; Weiss, E. Student Absenteeism: Who Misses School and How Missing School Matters for Performance; Economic Policy Institute: Washington, DC, USA, 2018.

22. Mendoza, D.L.; Benney, T.M.; Boll, S. Long-term analysis of the relationships between indoor and outdoor fine particulate pollution: A case study using research grade sensors. Sci. Total Environ. 2021, 776, 145778. [CrossRef]

23. Vardoulakis, S.; Giagloglou, E.; Steinle, S.; Davis, A.; Sleeuwenhoek, A.; Galea, K.S.; Dixon, K.; Crawford, J.O. Indoor exposure to selected air pollutants in the home environment: A systematic review. Int. J. Environ. Res. Public Health 2020, 17, 8972. [CrossRef]

24. American Lung Association. State of the Air 2021; American Lung Association: Chicago, IL, USA, 2021.

25. Pishue, B. INRIX 2020 Global Traffic Score Card; INRIX Research: Kirkland, WA, USA, 2020.

26. Horel, J.; Crosman, E.T.; Jacques, A.; Blaylock, B.; Arens, S.; Long, A.; Sohl, J.; Martin, R. Summer ozone concentrations in the vicinity of the Great Salt Lake. Atmos. Sci. Lett. 2016, 17, 480-486. [CrossRef]

27. Whiteman, C.D.; Hoch, S.W.; Horel, J.D.; Charland, A. Relationship between particulate air pollution and meteorological variables in Utah's Salt Lake Valley. Atmos. Environ. 2014, 94, 742-753. [CrossRef]

28. Mendoza, D.L.; Crosman, E.T.; Mitchell, L.E.; Jacques, A.; Fasoli, B.; Park, A.M.; Lin, J.C.; Horel, J. The TRAX Light-Rail Train Air Quality Observation Project. Urban Sci. 2019, 3, 108. [CrossRef]

29. Bulot, F.M.J.; Russell, H.S.; Rezaei, M.; Johnson, M.S.; Ossont, S.J.J.; Morris, A.K.R.; Basford, P.J.; Easton, N.H.C.; Foster, G.L.; Loxham, M.; et al. Laboratory comparison of low-cost particulate matter sensors to measure transient events of pollution. Sensors 2020, 20, 2219. [CrossRef]

30. ES-642; Dust Monitor Operation Manual. Met One Instruments, Inc.: Grants Pass, OR, USA, 2013.

31. Google Maps. Available online: https://www.google.com/maps (accessed on 26 December 2021).

32. USGS TNM Elevation Tool. Available online: https:/ /apps.nationalmap.gov/elevation/ (accessed on 26 December 2021).

33. Lareau, N.P.; Crosman, E.; Whiteman, C.D.; Horel, J.D.; Hoch, S.W.; Brown, W.O.; Horst, T.W. The persistent cold-air pool study. Bull. Am. Meteorol. Soc. 2013, 94, 51-63. [CrossRef]

34. Steenburgh, W.J.; Massey, J.D.; Painter, T.H. Episodic dust events of Utah's Wasatch Front and adjoining region. J. Appl. Meteorol. Climatol. 2012, 51, 1654-1669. [CrossRef]

35. United States Environmental Protection Agency. Air Quality Index (AQI) Basics. Available online: https://www.airnow.gov/ aqi/aqi-basics / (accessed on 2 January 2022).

36. Siegel, J.A.; Nazaroff, W.W. Predicting particle deposition on HVAC heat exchangers. Atmos. Environ. 2003, 37, 5587-5596. [CrossRef]

37. Deng, S.; Lau, J. Seasonal variations of indoor air quality and thermal conditions and their correlations in 220 classrooms in the Midwestern United States. Build. Environ. 2019, 157, 79-88. [CrossRef]

38. Zhang, J.J.; Wei, Y.; Fang, Z. Ozone pollution: A major health hazard worldwide. Front. Immunol. 2019, 2518. [CrossRef] 